\title{
MINDFULNESS AND SELF-EFFICACY IN AN ONLINE DOCTORAL PROGRAM
}

\author{
K.M. McCann, Grand Canyon University \\ Mendi Davis, Grand Canyon University
}

\begin{abstract}
The purpose of this quasiexperimental quantitative research study was to examine the extent to which a relationship exists between the use of mindfulness interventions and doctoral student self-efficacy in students enrolled in a doctoral program at a Christian university located in the southwestern United States. The theoretical foundation of self-efficacy developed by Bandura informed this study. The sample consisted of 19 doctoral students $(n=19)$ from a Christian university. Participants completed the SelfEfficacy Scale (SES) in the first week of the course and again in the final week of the course. Three groups were compared. One group was given interventions in weeks 2 and 7. The second group was given interventions in weeks 3, 4, 5, and 7. The third group was given interventions within weeks 2, 3, 4, 5, 6, 7, and 8. Data were analyzed using a one-way ANOVA. The researchers found no statistical significance between the use of mindfulness interventions and doctoral students' self-efficacy.
\end{abstract}

Keywords: mindfulness, online doctoral students, self-efficacy

\section{INTRODUCTION}

The increasing popularity of mindfulness practice and its associated benefits are forcing educators to explore its potential benefits in the classroom. Research indicates that mindfulness interventions, when appropriately integrated into the learning process (Davis, 2014; Mapel, 2012; Sherretz, 2011), may enhance student performance by reducing stress and anxiety levels (Marchand, 2012; Morledge et al., 2013; Soysa \& Wilcomb, 2013). Whether or not this correlates with enhanced self-efficacy is not well studied.

\section{MINDFULNESS}

Mindfulness is a concerted and open awareness cultivated by meditation rather than by adherence to rational, logical thought processes typically lauded in the West (Kabat-Zinn, 2005). The most sophisticated understanding of mindfulness comes from Buddhism and is practiced as a means to enhance empathy, compassion, and a realization that suffering comes from attachment to outcomes.
Mindfulness practice forces the practitioner to live in the moment, thereby experiencing each sensation and emotion just as it is, apart from attachment to expectation or judgment.

Mindfulness practice enhances emotional intelligence, self-regulation, and performance (Whitesman \& Mash, 2016) in both educational and corporate sectors. From medical applications of mindfulness practice (Baer, 2003; Davidson, 2000; Dobson, 2015; Kabat-Zinn, 2003) to those used in the educational setting (Davis, 2014; Mapel, 2012; Sherretz, 2011), degrees of improvement are apparent, though it is uncertain how, and to what extent, those interventions serve to improve student efficacy. The mindfulness research supports a relationship between strategic attentional control and mindfulness practice (Bogels, Sijbers, \& Voncken, 2006; Shapiro, Brown, \& Biegel, 2007; Valentine \& Sweet, 1999) as well as a relationship between mental health and mindfulness (Baer, 2003; Grossman, Niemann, Schmidt, \& Walach, 
2004; Lazar, 2005).

Mindfulness practice is intended to cultivate an attitude that thoughts are fleeting and our reactions to those thoughts are precursors for feeling (KabatZinn, 2005; Teasdale et al., 2002). The intent is to gradually reprogram responses and behaviors away from reacting to anxiety provoking triggers. The reprogramming results in the practitioners being able to evaluate events in a less reactionary framework. Once the practitioner is able to distinguish between thought and reality, they can learn to respond to negative thoughts without judgment.

Mindfulness is a deliberate awareness of external and internal experiences of the moment (Brown \& Ryan, 2006; Kabat-Zinn, 2003). There is ample research on the relationship between wellbeing, psychological distress, and mindfulness in college undergraduate students (Hinterman, Burns, Hopwood, \& Rogers, 2012; Howell, Dopko, Passmore, \& Buro, 2011; Jimenez, Niles, \& Park, 2010; Masuda \& Tully, 2012; Palmer \& Rodger, 2009; Roberts \& Danoff-Burg, 2010), but there is no information on the impact of mindfulness interventions on self-efficacy in online doctoral students.

\section{GENERAL SELF-EFFICACY}

Rather than a set of characteristic or beliefs that a person may or may not possess, self-efficacy is the belief in one's own ability and has been shown to play a major role in human achievement (Bandura, 1997). Self-efficacy is an internal, deep judgment of one's own self and capabilities to achieve certain levels of performance (Bandura, 1986) or individual assessments and perceptions of one's self in regard to effectiveness and competence (Gecas, 1986). Self-efficacy has been shown to be a pivotal concept where an individual's level of motivation, affective states, and actions are based upon what they believe rather than objectivity, and it is an attribute of cognitive, motivational, affective, and selection processes operating concert with one another (Bandura, 1986).

Self-efficacy often influences an individual's well-being through their coping approaches (Jex, Bliese, Buzzell, \& Primeau, 2001). Individuals with higher self-efficacy deal more effectively with complications, persevere through trials and problems, are more likely to accomplish expected outcomes, and derive greater satisfaction through completing tasks (Judge \& Bono, 2001). On the other hand, individuals with lower self-efficacy tend to use coping approaches that are more emotion-focused than problem-focused. The use of problem-focused coping has been shown to cause less physical and psychological stress (Liu, Siu, \& Shi, 2010). Numerous studies have shown that higher self-efficacy is connected to better health outcomes and well-being, while lower self-efficacy is connected to depression, job dissatisfaction, and burnout (Arslan, 2012; Bandura, 1997; Ghasemizad, Khajehei, \& Mohamadkhani, 2013; Judge \& Bono, 2001; Schyns \& von Collani, 2002; Siu, Lu, \& Spector, 2007).

\section{DOCTORAL STUDENTS}

Many doctoral students within the first several classes have concerns regarding their ability to master key concepts, write at a doctoral level, conduct research, and prepare to write a dissertation. Research has shown that lower selfefficacy within doctoral students can interfere with their willingness to conduct research (Love, Bahner, Jones, \& Nilson, 2007) while higher selfefficacy is an important factor related to students successfully conducting research and contributing to their field of study (Forester, Kahn, \& HessonMcInnis, 2004). The online environment often makes a significant contribution to the doctoral student self-efficacy (Baltes, Hoffman-Kipp, Lynn, \& Welzer-Ward, 2010).

To the knowledge of the authors, no study has investigated the relationship between mindfulness practice and the self-efficacy of online doctoral students. Evidence shows, however, that participants in mindfulness-based stress reduction programs report improvement in life satisfaction measures (Brown \& Ryan, 2006; Shapiro, Astin, Bishop, \& Cordova, 2005; Drydakis, 2011).

\section{METHODS}

Purpose

The purpose of this quantitative quasiexperimental study was to determine if there was a relationship between mindfulness interventions and student self-efficacy in an online doctoral program. The study was conducted to examine if weekly mindfulness interventions impacted student self-efficacy levels throughout an 
eight-week course. Students completed the General Self-Efficacy scale (GSE) (Schwarzer \& Jerusalem, 1995) during week one and then again during the final week of the course.

\section{Sample}

The sample for this quasiexperimental study included four sections of doctoral-level courses in psychology and educational leadership taught across sequential terms; all sections were taught completely online using the LoudCloud Management System. Two instructors facilitated the courses. The educational leadership instructor taught all EdD courses and utilized identical course structure, assignments, and instructional material for LDR 800 and LDR 802. The psychology instructor taught both PSY courses and utilized identical course structure, assignments, and instructional material for PSY 802 and PSY 803. Both instructors are experienced online teachers and have over fifteen years of combined teaching experience at the college level.

\section{Procedure}

Participants completed the General SelfEfficacy scale (Schwarzer \& Jerusalem, 1995) during Modules 1 and 8 of the course. During each Module, student-participants in groups $2 \mathrm{x}, 4 \mathrm{x}$, and $7 \mathrm{x}$ were asked to complete a Weekly Check-In survey designed to gauge their comfort level with the program. Students in the $2 \mathrm{x}, 4 \mathrm{x}$, and $7 \mathrm{x}$ groups were asked to engage in mindfulness intervention exercises prior to completing the Weekly CheckIns. The Check-In Tool was composed of the same questions each week.

In addition to the Weekly Check-In, students were asked to participate in a weekly mindfulness intervention. At the end of each Module, a Mindfulness/Self-Efficacy Thread was posted for that week and student-participants were asked to reflect on their experiences as they related to the tool.

To ensure students were aware of the interventions and Weekly Check-Ins, these pieces were highlighted on the course announcements page and in the discussion question introductions. In the two sections containing two interventions, exercises were added in weeks $X$ and $X$ for each of the eight weeks of the term in the following ways:

- In the $2 x$ condition, an intervention was added to the course announcements in weeks $X$ and $X$ - GSE in week 1 and 8. Interventions: Goal Visualization in week 3 and Finding Silver Linings in week 7.

- In the $4 \mathrm{x}$ condition, an intervention was added to the course announcements in weeks $\mathrm{X}, \mathrm{X}, \mathrm{X}$, and $\mathrm{X}-\mathrm{GSE}$ in week 1 and 8. Interventions: Goal Visualization in week 3, Gratitude Journal in week 4, Finding Silver Linings in week 5, and Best Possible Self in week 7.

- In the $7 x$ condition, an intervention was added to the course announcements in weeks. ... GSE in week 1 and 8. Interventions: Goal Visualization in week 2, Use Your Strengths in week 3, Selfcompassion Break in week 4, Finding Silver Linings in week 5, Best Possible Self in week 6, Capitalizing on Positive Events in week 7, Gratitude Journal in week 8.

All interventions were available via a PDF attachment from the course announcement page appearing on the initial screen of the course management system. During the final week of the term, students were asked to complete an online version of the General Self-Efficacy Survey (Schwarzer \& Jerusalem, 1995).

\section{Materials}

To examine the impact of the cumulative addition of interventions, four conditions were created across sequential terms of the courses. The target course was structured in weekly learning modules across an eight-week term. Each weekly module contained two threaded discussion assignments, written homework assignments, and three required substantive participation engagement assignments. The assignment rhythm and workload was the same across the LDR and the PSY courses for the online doctoral program. The conditions are outlined below:

- Control. The control section was the baseline measure to determine doctoral students' self-efficacy in the LDR and PSY courses prior to the addition of mindfulness intervention strategies.

- $2 x$ intervention. The $2 x$ intervention group was asked to participate in two mindfulness interventions during weeks 3 and 7 of the term. The interventions were selected from 
Table 1. P-Value $=0.123172$ More Than Specified 0.05, We Accept the Null as the Data Reveals There is No Statistical Significance

\begin{tabular}{|c|c|c|c|c|c|c|}
\hline \multicolumn{7}{|c|}{ ANOVA: Single Factor Summary } \\
\hline Groups & Count & Sum & Average & Variance & & \\
\hline Beginning W1 & 10 & 36.06 & 3.606 & 0.047093333 & & \\
\hline Ending W 8 & 10 & 34.66 & 3.466 & 0.027826667 & & \\
\hline \multicolumn{7}{|c|}{ ANOVA } \\
\hline $\begin{array}{l}\text { Source of } \\
\text { Variation }\end{array}$ & SS & df & MS & $\mathbf{F}$ & P-value & F cri \\
\hline Between Groups & 0.098 & 1 & 0.098 & 2.616123865 & 0.123172176 & 4.413873419 \\
\hline Within Groups & 0.67428 & 18 & 0.03746 & & & \\
\hline Total & 0.77228 & 19 & & & & \\
\hline
\end{tabular}

a list of mindfulness practices from the UC Berkeley Greater Good Science Center. Permission was obtained from UC Berkeley for their use. The GSE was used in weeks 1 and 8 . The Goal Visualization intervention was used in week 3. The Finding Silver Linings intervention was use in week 7.

- 4x intervention. The $4 x$ intervention group was asked to participate in two mindfulness interventions during weeks $3,4,5$, and 7 of the term. The interventions were selected from a list of mindfulness practices from the UC Berkeley Greater Good Science Center. Permission was obtained from UC Berkeley for their use. The GSE was used in weeks 1 and 8 . The following interventions were used: Goal Visualization in week 3, Finding Silver Linings in week 5 , best possible self in week 7.

- $7 \mathbf{x}$ intervention. The $7 x$ intervention group was asked to participate in two mindfulness interventions during weeks 2 through 8 of the term. The interventions were selected from a list of mindfulness practices from the UC Berkeley Greater Good Science Center. Permission was obtained from UC Berkeley for their use. The GSE was used in weeks 1 and 8 . The following interventions were used: Goal Visualization in week 2, Use Your Strengths in week 3, Self-compassion Break in week 4, Finding Silver Lining in week 5, Best Possible Self in week 6, Capitalizing on Positive Events in week 7, and the Gratitude Journal in week 8.

\section{Measures}

To permit a comparative analysis of the mindfulness interventions on student self-efficacy, two outcome measures were implemented during the term: The General Self-Efficacy (Schwarzer \& Jerusalem, 1995) was administered during week 1 of the course to establish a baseline and then again during week 8 to determine the effect, if any.

\section{General Self-Efficacy Test}

The General Self-Efficacy Test (Schwarzer \& Jerusalem, 1995) is a ten-item, self-report measure used to determine levels of self-efficacy. Respondents indicate their level of agreement on a five-point Likert-type scale $(1=$ not at all true of me; 5 = exactly true of me) to statements relative to self-efficacy such as "I can always manage to solve difficult problems if I try hard enough," and "I am confident that I could deal efficiently with unexpected events." Self-efficacy is scored by finding the sum of all items as correlated to emotion, optimism, work, and satisfaction.

P-value $=0.123172$ more than specified 0.05, we accept the null as the data reveals there is no statistical significance.

\section{RESULTS AND DISCUSSION}

The results of these comparisons, as listed in Table 1, indicated no significant differences in course engagement or learning between any of the various levels of intervention. While none of the analyses revealed significant differences between groups, it is interesting to note that males did show 
a slightly lower self-efficacy score during the Week 8 testing. This is likely due to there being more females enrolled in the courses than males.

The results of this study only described participants involved in the study; it is possible that with a smaller sample size these results can be generalizable to other populations. The findings of the study also were limited by the accuracy and perception of the participants. However, it is assumed that the students involved in the study responded honestly and interpreted the survey instrument as intended. While standardized directions were provided, there remains a possibility of variation in the interpretation of the survey language and how participants interpreted the questions.

The findings of the study were subject to the limitations of survey data collection methods. The researchers could not define the conditions under which the survey was completed since the survey was sent via email and was to be completed at the convenience of the participant. The findings of this study were based on Likert-type questions, which do not allow participants to construct their own responses or allow the researcher to probe for additional insight. Mindfulness and self-efficacy may be perceived in different ways by students.

Finally, doctoral students may already possess a higher than average degree of self-efficacy, hence their enrollment in a terminal degree program. The sample population itself may not be a comprehensive representation of self-efficacy status in a graduate online program. Participants in an undergraduate or Master's program may provide a more accurate view of self-efficacy transformation during an online postsecondary education program.

\section{LIMITATIONS}

The results were limited by the reliability and validity of the General Self-Efficacy Scale (GSE). This study utilized a survey research design based on students' self-reporting of self-efficacy. The survey responses were limited to 16 total classes within a four-month period during the first quarter of 2017, and thus the research was unable to evaluate any effects that might have occurred prior to the survey or after obtaining the survey responses. The survey of doctoral students was conducted within only a single college in southwestern Arizona, which limits the demographic sample; however, students from the college do reside throughout the country. This research study had a sample size of 19 students located within Arizona, which could limit the generalizability to other regions or environments. The study was conducted in only two courses in the doctoral program. Limiting the study to those two courses may not be representative of the program as a whole. This study was conducted at a Christian university, which certainly limits the scope of the research.

\section{FUTURE RECOMMENDATIONS}

An open-ended qualitative feedback session at the end of each course may yielded richer data in terms of mindfulness intervention impact. It is possible that the interventions influenced behaviors that were not measured on the GSE. The GSE may not accurately or directly reflect the impact of the interventions themselves, as they only measure a single point in time and mindfulness intervention, by its nature, is fluid, on-going, and evolves over time depending on the situation. Future research could include samples from secular institutions to determine if the findings of this study hold true in those contexts. 


\section{REFERENCES}

Arslan, A. (2012). Predictive power of the sources of primary school students' self-efficacy beliefs on their self-efficacy beliefs for learning and performance. Educational Sciences: Theory \& Practice, 12(3), 1915-1920.

Baer, R. A. (2003) Mindfulness training as a clinical intervention: A conceptual and empirical review. Clinical Psychology: Science and Practice, 10(2), 125-143. doi.org/10.1093/clipsy.bpg015

Baltes, B., Hoffman-Kipp, P., Lynn, L., \& Weltzer-Ward, L. (2010). Students' research self-efficacy during online doctoral research courses. Contemporary Issues in Education Research, 3(3), 51-58.

Bandura, A. (1986). Social foundations of thought and action. A social cognitive theory. Englewood Cliffs, NJ: Prentice-Hall.

Bandura, A. (1997). Self-efficacy. Harvard Mental Health Letter, 13(9), 4.

Bogels, S. M., Sijbers, G.F.V.M., Voncken, M. (2006). Mindfulness and task concentration training for social phobia: A pilot study. Journal of Cognitive Psychotherapy, 20(1), 33-44. doi:10.1891/jcop.20.1.33

Brown K. W. \& Ryan R. M. (2006). Perils and promise in defining and measuring mindfulness: Observations from experience. Clinical Psychology: Science and Practice, 11(3), 242-248. doi.org/10.1093/clipsy.bph078

Davidson, R. J. (2000). Affective style, psychopathology and resilience: Brain mechanisms and plasticity. American Psychologist, 55(11), 1196-1214.

Davis, D. J. (2014). Mindfulness in higher education: Teaching, learning, and leadership. International Journal of Religion and Spirituality in Society, 4(3), 1-6.

Dobson, P. L. (2015). Introduction: Mindful medical practice. In Dobson, P. L. (Ed.), Clinical Narratives and Therapeutic Insights (pp. 1-5). Montreal, Canada: Springer. doi:10.1007/978-3-319-15777-1_1

Drydakis N. (2012). Health-impaired employees' job satisfaction: New evidence from Athens, Greece. Applied Economics Letters, 19(8), 789-793. doi:10.1080/13504851.2011.605346

Forester, M, Kahn J. H., \& Hesson-McInnis, M. (2004). Factor structures of three measures of research selfefficacy. Journal of Career Assessment, 12(1), 3-16. doi:10.1177/1069072703257719

Gecas, V. (1989). The social psychology of self-efficacy. Annual Review of Sociology, 15, 291-316. doi:10.1146/annurev. so.15.080189.001451
Ghasemizad, A., Khajehei, H., \& Mohamadkhani, K. (2013). School level environment and elementary teachers' self-efficacy: Structural equation model. Australian Journal of Basic \& Applied Sciences, 7(8), 589-594.

Grossman, P., Niemann, L., Schmidt, S., \& Walach, H. (2004). Mindfulness-based stress reduction and health benefits: A meta-analysis. Journal of Psychosomatic Research, 57(1), 35-43. doi:10.1016/S0022-3999(03)00573-7

Hinterman, C., Burns, L., Hopwood, D., \& Rogers, W. (2012). Mindfulness: Seeking a more perfect approach to coping with life's challenges. Mindfulness, 3, 275-281. doi:10.1007/ s12671-012-0091-8

Howell, A. J., Dopko, R. L., Passmore, H., \& Buro, K. (2011). Nature connectedness: Associations with well-being and mindfulness. Personality and Individual Differences, 51, 166-171. doi:10.1016/j. paid.2011.03.037

Jex, S. M., Bliese, P. D., Buzzell, S., \& Primeau, J. (2001). The impact of self-efficacy on stressor-strain relations: Coping style as an explanatory mechanism. Journal of Applied Psychology, 86(3), 401-409.

Jimenez, S. S., Niles, B. L., \& Park, C. L. (2010). A mindfulness model of affect regulation and depressive symptoms: Positive emotions, mood regulation expectancies, and self-acceptance as regulatory mechanisms. Personality and Individual Differences, 49, 645-650. doi:10.1016/j. paid.2010.05.041.

Judge, T. A., \& Bono, J. E. (2001). Relationship of core selfevaluations traits-self-esteem, generalized self-efficacy, locus of control, and emotional stability-with job satisfaction and job performance: A meta-analysis. Journal of Applied Psychology, 86(1), 80-92. doi:10.1037//0021-9010.86.1.80

Kabat-Zinn, J. (2003). Mindfulness: The heart of rehabilitation. In Leskowitz, E. (Ed.), Complementary and alternative medicine in rehabilitation (pp. xi-xv). Saint Louis, MO: Churchill Livingtsone.

Kabat-Zinn, J. (2005). Coming to our senses: Healing ourselves and the world through mindfulness. New York, NY: Hyperion.

Lazar, S. W. (2005). Mindfulness research. In C. K. Germer, R. D. Siegel, \& P. R. Fulton (Eds.), Mindfulness and psychotherapy (pp. 220-238). New York, NY: Guilford Press.

Liu, J., Siu, O., \& Shi, K. (2010). Transformational leadership and employee well-being: The mediating role of trust in the leader and self-efficacy. Applied Psychology: An International Review, 59(3), 454-479. doi:2048/10.1111/j.14640597.2009.00407.x 
Love, K. M, Bahner, A. D, Jones, L. N., \& Nilson, J. E. (2007). An investigation of early research experience and research selfefficacy. Professional Psychology: Research and Practice, 38(3), 314-320. doi:10.1037/0735-7028.38.3.314

Mapel, T. (2012). Mindfulness and education: Students' experience of learning mindfulness in a tertiary classroom. New Zealand Journal of Educational Studies, 47(1), 19-32.

Marchand, W. (2012). Mindfulness-based stress reduction, mindfulness-based cognitive therapy, and Zen meditation for depression, anxiety, pain, and psychological distress. Journal of Psychiatric Practice, 18(4), 233-252. doi:10.1097/01. pra.0000416014.53215.86

Masuda, A., \& Tully, E. C. (2012). The role of mindfulness and psychological flexibility in somatization, depression, anxiety, and general psychological distress in a nonclinical college sample. Journal of Evidence-Based Complementary \& Alternative Medicine, 17, 66-71. doi:10.1177/2156587211423400

Morledge, T. J., Didier, A., Fox, E., Fu, A., Higashi, M. K., Kruzikas, D. T . . Reese, P. R. (2013). Feasibility of online mindfulness program for stress management-A randomized, controlled trial. Anthology of Behavioral Medicine, 46(2), 137-148. doi:10.1007/s12160-013-9490-x

Palmer, A., \& Rodger, S. (2009). Mindfulness, stress, and coping among university students. Canadian Journal of Counselling, 43, 198-212.

Roberts, K. C., \& Danoff-Burg, S. (2010). Mindfulness and health behaviors: Is paying attention good for you? Journal of American College Health, 59, 165-173. doi:10.1080/0744848 1.2010.484452

Schwarzer, R., \& Jerusalem, M. (1995). Generalized Self-Efficacy scale. In J. Weinman, S., Wright, \& M. Johnston (eds.). Measures in health psychology: A user's portfolio: Causal and control beliefs (pp. 35-37). Windsor, UK: NFERNELSON.

Schyns, B., \& von Collani, G. (2002). A new occupational selfefficacy scale and its relation to personality constructs and organizational variables. European Journal of Work and Organizational Psychology, 11(2), 219-241. doi:10.1080/13594320244000148

Shapiro S. L., Astin J. A., Bishop S. R., \& Cordova M. (2005). Mindfulness-based stress reduction for health care professionals: Results from a randomized trial. International Journal of Stress Management, 12(2), 64-176. doi:10.1037/1072-5245.12.2.164
Shapiro, S. L., Brown, K., \& Biegel, G. (2007). Self-care for health care professionals: Effects of MBSR on mental well being of counseling psychology students. Training and Education in Professional Psychology, 1, 105-115.

Sherretz, C. E. (2011). Mindfulness in education: Case studies of mindful teachers and their teaching practices. Journal of Thought, 46(3), 79-96.

Siu, O.L., Lu, C.Q., \& Spector, P. E. (2007). Employees' well-being in greater China: The direct and moderating effects of general self-efficacy. Applied Psychology: An International Review, 56(2), 288-301. doi:10.1111/j.1464-0597.2006.00255.x

Soysa, C. K., \& Wilcomb, C. J. (2013). Mindfulness, selfcompassion, self-efficacy, and gender as predictors of depression, anxiety, stress, and well-being. Mindfulness, 6(2) 217-226. doi:10.1007/s12671-013-0247-1

Teasdale, J. D., Moore, R. G., Hayhurst, H., Pope, M., Williams, S., \& Segal, Z. V. (2002). Metacognitive awareness and prevention of relapse in depression: Empirical evidence. Journal of Consulting and Clinical Psychology, 70, 278-287.

Valentine, E. R., \& Sweet, P. L. G. (1999). Meditation and attention: A comparison of the effects of concentrative and mindfulness meditation on sustained attention. Mental Health, Religion and Culture, 2(1), 59-70. doi:10.1080/13674679908406332

Whitesman, S. \& Mash, R. (2016). Examining the effects of mindfulness-based distance learning professional training module on personal and professional functioning: A qualitative study. BMC Medical Education, 16, doi:10.1186/ s12909-016-0810-2 